\title{
Considerations in the reliability of occlusal indicators and occlusal contact marks
}

\author{
Chang-Hwan Kim, Dae-Gon Kim, Kyung-Ho Ko, Yoon-Hyuk Huh, Lee-La Cho, Chan-Jin Park* \\ Department of Prosthodontics \& Research Institute of Oral Science, College of Dentistry, Gangneung-Wonju National University, \\ Gangneung, Republic of Korea
}

On the reliability of occlusal contact marks with occlusal indicators, it must be important to consider the affecting results of using methods. With affecting the accuracy and validity of results, there are many variables such as thickness and material of indicator, occlusal force, number of usage and etc. Nevertheless, researches on the occlusal contact marks have limited to focusing thickness of indicators and occlusal force. For the control of variables, it is clinically recommended to do use new indicators in every trial and to secure dry condition and to use thinner ones. In addition, alternatives might be helpful to understand more appropriate results. (J Dent Rehabil Appl Sci 2018;34(3):147-56)

Key words: occlusal contact; occlusal indicator; reliability; accuracy; validity

\begin{abstract}
서론
교합점 기록재는 교합을 확인하는 목적으로 흔히 사용 되고 있다. 잉크가 함유된 교합지(articulating paper)는 교합점의 기록뿐만 아니라 교합 운동을 기록하고 확인하 고자 사용하고 있고 교합조정 후 교합의 확인을 위해서 필수적으로 사용하는 도구이다. ${ }^{1-3}$

교합점을 기록하는데 있어서 잉크를 이용하는 재료 는 교합지, 교합 호일(articulating foil), 교합 실크(articulating silk) 등이 있다. 이들은 질적 방법(qualitative method)으로 교합의 순서, 접촉의 밀도는 알 수 없는 한 계가 있다. 반면, 컴퓨터를 이용하여 교합의 양상을 기록 하는 장치는 대표적으로 T-scan ${ }^{\circledR}$ (Tekscan Inc., Boston, USA)이 있다. 이 장치는 양적 방법(quantitative method)

*Correspondence to: Chan-Jin Park Professor, Department of Prosthodontics \& Research Institute of Oral Science, College of Dentistry, Gangneung-Wonju National University, Jukheongil 7, Gangneung, 25457, Republic of Korea

Tel: +82-33-640-3153, Fax: +82-33-640-3103, E-mail: doctorcj@gwnu.ac.kr

Received: May 13, 2018/Last Revision: June 11, 2018/Accepted: June 14, 2018
\end{abstract}

으로 교합관계, 교합의 순서, 접촉의 밀도를 알 수 있다 는 장점이 있다. ${ }^{4,5}$

역사적으로 교합을 확인하기 위해 오래 전부터 사용된 치과용 왁스나 인상재부터 최근의 $\mathrm{T}-\operatorname{scan}^{\circledR}$ 까지 다양한 방법이 시도되어 왔다. 하지만 어떠한 방법도 정확도, 신 뢰도 측면에서 모두 만족하는 재료는 없었고 각기 나름 의 한계가 존재하였다. ${ }^{6}$ 이 때문에 교합점 기록재는 여러 문헌에서 흔하게 사용되어 왔고 교합점의 분석 방법에 대해 자세히 설명되고 있음에도 불구하고 ${ }^{1-3}$ 교합점 기록 만을 이용한 교합분석이 타당한 방법인지에 대해서는 논 란의 여지가 있다. 본 문헌고찰에서는 교합점 기록재를 통한 교합분석의 타당성에 대해 알아보고, 정확한 교합 분석을 위한 임상적 고려사항에 대해 정리해 보고자 하 였다.

Copyright@ 2018 The Korean Academy of Stomatognathic Function and Occlusion. (c) It is identical to Creative Commons Non-Commercial License. 


\section{문헌 고찰}

교합점 기록재를 통해 교합을 분석하는 방법이 타당 한가에 대해서는 정확도, 신뢰도, 교합분석 방법이 결과 에 미칠 수 있는 영향 등을 고려해야 한다. ${ }^{7}$ 여러 가지 변 수들이 교합점 기록재에 미치는 영향을 연구한 문헌들을 통해 타당성에 대해 고찰해 보고자 한다(Table 1).

\section{1. 정확도 - 두께}

교합점 기록재를 이용한 분석은 교합점의 수와 면적 을 이용한다. 특히 교합점은 교합접촉을 정확하게 나타 내는지가 위양성(false positive)으로 인한 잘못된 교합조 정의 결과로 이어질 수 있기 때문에 중요하게 여겨져 왔 다. 이에 대하여 가장 많은 문제제기가 된 변수는 교합 점의 두께였다. Halperin 등 ${ }^{8}$ 은 너무 두꺼운 교합점 기록 재는 접촉이 아니더라도 치아 사이 공간보다 교합점 기 록재가 두께로 인해 위양성을 보일 수 있고, 고유수용성 감각을 자극하여 턱을 편향되게 할 수 있다고 지적하였 다. 비록 교합점 기록재의 두께가 위양성을 보이도록 하 는지, 고유수용성 감각을 자극하는지를 실험한 것은 아 니었지만 이 주장은 현재까지도 널리 받아들여지고 있 다. Carossa 등 ${ }^{9}$ 은 교합기에 장착한 모형을 이용하여 실 험한 결과, $8 \mu \mathrm{m}$ 두께의 교합지보다는 $40 \mu \mathrm{m}$ 두께의 교 합지가 더 넓은 교합점 면적을 나타냈다고 보고하였다. 또한 $40 \mu \mathrm{m}$ 는 $8 \mu \mathrm{m}$ 의 경우보다 교합 접촉 시간이나 교 합력 등 다른 변수에 의한 면적의 변화가 적었다고 보고 하였다. Brizuela-Velasco 등 ${ }^{10}$ 은 소구치나 대구치의 임 플란트 고정성 보철물을 시행한 환자를 대상으로 한 in vivo 실험에서 교합지의 두께가 두꺼울수록 덜 정형화 된 교합점 형태와 더 큰 교합점의 면적이 나타났고 가장 얇
은 교합지에서 나타난 모든 교합점은 두꺼운 교합지에서 도 모두 나타났다고 보고하였다. 더 나아가, 교합점의 양 상을 분석한 결과 얇은 교합점 기록재에서 나타난 교합 점 부분은 교합점 기록재의 두께가 두꺼워질수록 오히려 채도가 낮아지는 경우가 있음을 발견하였다. 이는 두꺼 운 교합지에서 표시가 약한 부분이 오히려 더 강한 교합 을 형성하고 있을 가능성을 시사한다. 반면, Millstein과 $\mathrm{Maya}^{11}$ 는 교합지의 두께가 같더라도 브랜드가 다르거나 잉크를 전달하는 매개물질이 다르다면 교합점의 면적은 다양하게 나온다고 보고하였다. 특히 두께만을 변수로 하여 평가하였을 때, $200 \mu \mathrm{m}$ 두께의 교합지가 나타내는 접촉점 중 가장 넓은 교합면적을 보이는 접촉점을 이용 하여 평가했을 때야 비로소 두께에 따른 통계적으로 유 의미한 차이가 나타났다고 하였다. 심지어 $200 \mu \mathrm{m}$ 두께 의 한 교합점 기록재는 $40 \mu \mathrm{m}$ 두께의 교합점 기록재보다 평균적으로 더 작은 면적의 교합점을 나타냈다고도 하 였다. 이를 통해 교합점 기록재에는 매우 많은 변수가 존 재하기 때문에 두께만을 변수로 볼 수 없다고 지적하였 다. Saraçoğlu와 Ozpinar ${ }^{5}$ 는 서로 다른 두께의 여러 교합 점 기록재를 이용해 교합점의 위치를 기록하고, 교합점 의 수가 변화하는 양상을 분석한 결과 두께에 따른 유의 미한 차이를 발견하지 못하였다. 오히려 두께보다는 교 합점 기록재의 종류나 브랜드에 따라 차이가 나타났음 을 보고하며 두께의 차이 외에도 수많은 변수의 가능성 을 시사하였다. Schelb 등 ${ }^{12}$ 은 평평한 면에 교합점 기록재 의 유연성, 교합력, 움직임, 교합이 가해지는 면적을 일정 하게 한 상태로 실험한 결과 두께에 따라 교합점 면적의 차이가 나타났음을 보고하였다. 종합하여 볼 때, 교합점 의 두께를 달리 해가며 분석할 필요가 있을 때에는 두께 외에 특성의 차이가 다양하게 나타나는 교합점 기록재를 함께 사용하지 않는 것이 추천된다. 아울러 두께가 두꺼

Table 1. Indicators and variables for occlusal contact marks

\begin{tabular}{lll}
\hline Indicators & & Variables \\
\hline Articulating paper & Thickness & Ductility \\
Articulating film & Occlusal load & The number of stroke \\
Articulating silk & Transferring medium & Surface roughness \\
Articulating nylon & Color & Surface material \\
Articulating foil & Plastic deformation & surface morphology \\
T-scan ${ }^{\circledR}$ Sensor & Dryness/wetness & Type of indicator \\
Etc. (Shimstock, tape, ribbon, cellophane warpper) & Operator experience & \\
\hline
\end{tabular}


울수록 위양성이 나타날 가능성이 높으므로 교합점 분석 시 최종 확인은 가능한 얇은 교합점 기록재를 사용할 것 이 추천된다고 여겨진다.

\section{2. 정확도 - 교합력}

교합점 기록재의 정확도와 교합력의 관계에 대한 연구 도 제시되었다. Carey 등 $^{13}$ 은 교합력을 달리 하며 공통적 으로 나타난 교합점 600 개를 분석한 결과, 전반적으로 교합력이 커질수록 교합점의 면적이 증가하는 경향이 나 타났으나, 그 일치도는 $21 \%$ 에 지나지 않았다고 보고하 였다. 이와 같은 결과는 임상가들이 믿고 있는 교합력과 면적과의 상관관계는 일치하지 않을 수도 있음을 시사한 다. Saad 등 $^{14}$ 은 교합력에 따른 교합점의 면적 및 교합점 의 수를 비교한 연구를 통해 교합력에 의해서 나타난 차 이를 면적이나 교합점 수로 확인할 수 없음을 보고하였 다. 반면, Reiber 등 ${ }^{15}$ 은 교합지나 교합 실크와는 달리 교 합 호일은 약한 교합력 하에서는 교합점 형성도가 낮아 짐을 보고하며, 교합 호일을 사용할 때에는 강하게 교합 하도록 지시하여야 한다고 주장하였다. 특정한 교합점 의 교합력에 대한 연구도 있었다. Qadeer 등 ${ }^{16}$ 은 30 명을 대상으로 교합지를 이용하여 기록한 교합점에 대하여 T$\operatorname{scan}^{\circledR}$ 을 활용한 교합력 검사를 시행한 결과, 제일 넓은 교합점이 실제로 가장 강한 교합점인 경우는 $38.3 \%$ 였고, 그 중 실제로 교합력을 반영하여 교합점의 크기가 나타 난 것은 7\% 뿐이었다고 보고하였다. Kerstein과 Radke ${ }^{17}$ 는 295명의 임상가들에게 교합점 사진을 촬영하여 가장 강한 교합점과 가장 약한 교합점을 선택하게 한 결과 약 $12.5 \%$ 의 정답률을 보였다고 보고하였다. 12점 만점으로 환산하였을 때 대부분이 0 점에서 2점 사이의 점수를 보 였으며 이 때 임상가의 임상 경험, 교합 교육 수준은 점 수에 영향을 끼치지 못했다고 지적하였다. 즉, 교합점 외 의 다른 정보 없이 교합력의 세기를 판단하는 것은 부정 확한 방법임을 나타낸다. 152명의 임상가를 대상으로 유 사하게 진행된 Sutter의 연구 ${ }^{18}$ 에서도 정답률이 $13.13 \%$ $16.67 \%$ 에 지나지 않았다고 보고하였다. 결론적으로 교 합점의 수, 형태, 넓이는 교합력을 반영하지 못하며, 교합 호일을 제외하면 환자에게 강하게 물게 하는 것은 교합 점 형성에 큰 차이를 불러일으키지 못할 것으로 추측된 다, 또한 형성된 각각의 교합점 형태나 넓이를 통해 교합 력의 크기를 예단해서도 안 된다고 할 수 있다.

\section{3. 정확도 - 그 외 여러 변수들}

교합점 기록재는 교합점을 형성하는데 있어 여러 변 수들이 동시에 존재할 수 있으며, 그 변수들이 결과에 영향을 끼칠 수 있는가 여부도 중요하다. Saraçoğlu와 Ozpinar ${ }^{5}$ 는 교합점 기록재의 두께 외에도 사용횟수, 젖 음 환경이 교합점 형성에 미칠 수 있는 영향에 대해 연구 하였다. 연구 결과 같은 교합지를 한 번 교합하였을 때에 비해 두 번째, 세 번째 교합으로 진행할수록 교합점 수의 감소가 나타남을 보고하였다. 이는 여러 차례 사용한 교 합점 기록재는 정보적 가치가 떨어지므로 교합점 기록재 는 자주 바꿔주고 가능하다면 매 회 새 것을 사용하는 것 이 그나마 정확한 결과에 가깝움을 의미한다. 또한, 구 강 환경에 따른 교합점 기록재의 민감도 변화를 in vivo 실험을 통해 확인하였다. 그 결과 젖은 환경은 마른 환경 에 비해 교합점 기록재의 민감도가 크게 감소하였다. T$\operatorname{scan}^{\circledR}$ 을 제외한 교합지, 교합 호일, 교합 실크 모두 큰 감소가 나타났다. 이와 관련하여 Qadeer 등 $^{16}$ 은 실험 설 계에 있어서 교합점 기록능력 향상을 목적으로 바셀린 (petroleum jelly)을 이용했다. 하지만 이와 관련한 확실 한 근거는 현재 찾아볼 수 없었다. 결론적으로 교합점 기 록재의 사용에 있어서 치아에 교합점 기록을 남기는 경 우 구강 환경의 습윤도 통제가 필수적이라고 할 수 있다. Carossa 등 ${ }^{9}$ 은 모형을 이용하여 전문가와 치과대학생이 교합점을 형성하였을 때 교합점의 면적과 수를 비교한 결과 술자의 숙련도나 교합 접촉 시간에 의해서도 교합 점의 면적이 달라질 수 있음을 보고하였다. Schelb 등 ${ }^{12}$ 은 교합지의 필름 재료, 매개물질에 따라 교합점의 면적이 변할 수 있다고 하였고, Millstein과 Maya ${ }^{11}$ 는 교합점 기 록재의 색상, 매개물질, 브랜드 등에 따라서도 교합점의 면적이 변할 수 있다고 주장하였다. Reiber 등 ${ }^{19}$ 은 교합지 와 교합 실크의 두께와 불요성(less flexibility)이 위양성 교합점을 많이 나타나게 할 수 있다고 지적하였다. 뿐만 아니라 교합 실크의 경우 차갑고 폐쇄된 환경에 보관하 지 않으면 매개 물질이 건조되어 교합점 형성 능력을 상 실할 수 있다고 지적하며 재료의 보관법에 관한 요소도 중요함을 주장하였다. Reiber 등 ${ }^{15}$ 은 다른 실험에서 교합 점이 기록되는 보철물의 재료, 표면 거칠기 등에 의해서 도 변화가 나타날 수 있음을 보고하였다. 아크릴 재료 상 에서는 교합점이 잘 기록되었고, 세라믹 상에서는 교합 점이 잘 기록되지 않았으며 연마가 되지 않은 경우가 더 잘 기록되었다고 보고하였다. 뿐만 아니라 교합 호일의 
경우 잘 연마된 세라믹, 아말감 상에는 교합점이 잘 기록 되지 않음을 보고하였다. 이와 같은 문헌들을 종합하여 볼 때, 비록 많은 연구가 이루어지지는 않았으나 교합점 기록재는 세세한 변수에 의해서도 큰 변화가 나타날 것 이 우려되므로 사용 시 가능한 최대로의 변수통제가 필 요하며, 충분히 변수가 통제되지 않은 경우 교합점 기록 재를 통한 분석은 충분한 정확도를 확보하지 못하였다 고 할 수 있다.

\section{4. 신뢰도와 반복재현성}

교합점 기록재의 신뢰도는 가장 평가하기 어려운 항 목 중 하나이다. 교합점의 위치, 면적, 수의 일관성을 통 해 신뢰도를 평가하고자 하는 노력이 있었다. Millstein과 $\mathrm{Maya}^{11}$ 는 교합점 기록재의 반복재현성 평가는 널리 쓰이 거나 명확하게 확립된 방법이 없다고 하였다. 같은 조건 하에서 동일한 교합지가 기록한 교합점 면적에 대해 급 내상관계수(intraclass correlation coefficient)를 조사한 결과 두께 $20 \mu \mathrm{m}, 40 \mu \mathrm{m}, 80 \mu \mathrm{m}$ 는 매우 낮아 신뢰할 수 없는 방법이라고 하였다. 또한 교합지의 반복재현성 평 가를 위하여 각 면적의 최대값, 최소값을 조사한 결과 평 균적으로 약 2 배 차이가 나타났으며 최소 1.24 배에서 최 대 3.63배까지 다양한 결과가 나타났다. 이를 통해 다른 모든 요소가 동일함에도 불구하고 면적의 편차가 크게 나타나는 재료는 반복재현성이 낮다고 할 수 있다고 결 론지었다. Anderson 등 ${ }^{20}$ 은 심스탁(shim stock)과 교합 지를 이용하여 24명을 대상으로 조사한 결과, 두 명의 검 사자 간 신뢰도는 심스탁이 더 높다고 보고하였다. 치아 별로 검사를 했을 때도 심스탁에 비해 교합지가 $10 \%$ 정 도 낮은 신뢰도를 나타냈으며, 이는 교합지의 재현성이 떨어지기 때문이라고 분석하였다. 즉, 교합점 기록재 단 독으로 충분한 신뢰도 및 반복재현성이 확보되지 않으므 로 보조적인 수단의 필요성이 제기된다. 이에 관해 심스 탁은 교합점 기록재에 대하여 보조적으로 사용되고 있는 대표적인 재료이다. 하지만 심스탁이 감지할 수 있는 미 세간극과 교합력에 따른 심스탁 제거 시 필요 힘을 연구 한 Harper와 Setchell에 따르면 ${ }^{21}$ 심스탁은 0 에서 $4 \mu \mathrm{m}$ 까지는 제거 시 필요 힘이 최대치로 같게 나타나고 $6 \mu \mathrm{m}$ 까지는 구분이 가지 않을 수 있음을 지적하였다. 또 교합 력이 늘어나면 심스탁을 제거하는데 필요한 힘이 늘어남 도 확인하였다. 결국 심스탁의 신뢰도가 더 높다고 하더 라도 정확한 미세간극이나 교합력의 측정에 있어서는 한
계가 있을 것으로 판단된다.

양적 방법을 이용한 신뢰도 평가 연구도 제시되었다. $\mathrm{Maness}^{22}$ 는 실제 접촉이 이미 알려진 에폭시 레진 모형을 이용하여 교합지, 심스탁, T-scan ${ }^{\circledR}$ 의 신뢰도를 비교한 결 과 교합지, 심스탁의 신뢰도가 T-scan ${ }^{\circledR}$ 에 비해 낮았다고 보고하였다. 교합지는 많은 위양성 때문에 낮은 신뢰도 를, 심스탁은 정확한 위치 특정의 면에서 부족하였다고 지 적하였다. Gazit 등 ${ }^{23}$ 은 Photo-occlusion technique을 이 용하여 교합 호일의 신뢰도를 비교한 결과 두 방법 모두 충분히 높은 반복재현성을 확보하지 못하였으나, Photoocclusion technique이 더 높은 신뢰도를 보였다고 하였 다. 하지만 양적 방법이 완전히 신뢰할 수 있는 지에는 의문이 있다. Saraçoğlu와 Ozpinar의 연구 ${ }^{5}$ 에 의하면 T$\operatorname{scan}^{\circledR}$ 센서는 2회 사용 때부터 민감도가 감소함을 보고 하였다. 다만, T-scan ${ }^{\circledR}$ 은 센서의 민감도를 소프트웨어적 으로 조정할 수 있으므로 이는 큰 문제가 되진 않을 것으 로 보인다. ${ }^{24-26}$ 그럼에도 불구하고, T-scan ${ }^{\circledR}$ 을 이용하여 교합 분석을 시행할 시에는 가급적 적은 횟수로 새로운 센서를 사용하여 측정할 것이 권장된다. T-scan ${ }^{\circledR}$ 센서는 센서 내 센실(sensel)이라 부르는 여러 센서가 들어있는 데, Throckmorton 등 ${ }^{25}$ 은 날카로운 압력에 의해 센실이 손상될 수 있는 점, 하나의 교합력을 몇 개의 센실이 기록 했는지 다를 수 있다는 점 등에 의해 교합력이 다양하게 나타날 수 있다고 지적하였다. 이를 극복하기 위해서는 센서에 보호 장치를 끼워야 하며, 그렇지 않은 채로 교합 을 측정할 시 센서 각각마다 서로 다른 값을 보여 충분한 신뢰도가 확보되지 않음을 보고하였다. Cerna 등 $^{26}$ 은 T$\operatorname{scan}^{\circledR}$ 센서의 신뢰성 측정을 위해 서로 다른 연도에 출시 된 센서 시리즈를 비교하였다. 그 결과, 센서 시리즈들은 출시된 연도에 따라 약 2.5 배 정도 서로 다른 민감도를 나타내어 상호 간 신뢰도가 충분히 확보되지 않음을 보 고하였다. 실험을 통해 T-scan ${ }^{\circledR}$ 은 절대적 교합력의 측정 이 아닌, 어느 위치에 어느 순간에 교합접촉이 나타나고 그 힘이 어떻게 분산되는가를 평가하는데 한정하여 유용 한 방법이라고 하였다. 결과적으로 $\mathrm{T}-\operatorname{scan}^{\circledR}$ 은 센서마다 서로 다른 민감도를 지니므로, 여러 T-scan ${ }^{\circledR}$ 센서로 측정 한 기록들을 상호간 비교하는 것은 충분히 신뢰할 만한 방법이 될 수 없을 것으로 판단된다. 다만, 이와 같은 양 적 방법의 한계에도 불구하고 교합점 기록재들은 전반적 으로 심스탁이나 양적 방법에 비해 낮은 신뢰도 혹은 반 복재현성을 나타내므로 면밀한 교합분석이 필요한 경우 이들을 보조적인 수단으로 이용하는 것이 추천된다. 


\section{5. 교합점 기록재가 교합 관계에 미치는 영향}

교합점 기록재의 두께, 가소성 등의 물리적 특성은 환 자의 교합 상황 그 자체를 변화시킬 수 있음이 지적되어 왔다. 즉, 교합지 혹은 $\mathrm{T}-\mathrm{scan}^{\circledR}$ 센서를 이용하여 채득한 교합관계가 그 자체로 본래 환자가 가지고 있는 교합관 계가 맞는지에 대한 논쟁이다. 먼저 교합점 기록재가 환 자의 근육, 관절 등의 변화를 일으켜서 교합 관계 자체 를 변화시킬 가능성에 대한 것이다. Forrester 등은 교 합과 관련된 근육인 temporalis anterior muscle (TA)와 superficial masseter muscle (MS)에 대한 surface electromyography (SEMG) 분석을 통해 교합점 기록재가 근 육의 활성도에 미치는 영향을 조사하였다. 또한 실험 대 상에게 설문지를 작성하도록 하여 교합점 기록재를 물 때 영향을 준 정도, 편안함, 질감, 단단한 정도를 7점 만 점으로 표현하도록 하였다. 그 결과 가장 소성을 보이면 서도 비교적 두꺼운 T-scan ${ }^{\circledR}$ 센서 $(96 \mu \mathrm{m})$ 와 두께가 두꺼 운 교합지 $(202 \mu \mathrm{m})$ 가 $\mathrm{MS}$ 에 영향을 끼친 것으로 나타났 다. 설문지에 대한 대답에서도 두 교합점 기록재가 유의 미하게 높은 점수를 나타내었다. T-scan ${ }^{\circledR}$ 센서의 두께와 소성의 물리적 특성에 대해 몇몇 연구자들은 SEMG 분 석 결과 T-scan ${ }^{\circledR}$ 센서를 물고 있을 때 코튼 롤을 물고 있 는 것과 같은 정도의 근육 활성도가 나타났다고 보고하 였다. Augusti 등 ${ }^{27}$ 은 $40 \mu \mathrm{m}$ 의 교합지, $200 \mu \mathrm{m}$ 의 교합지 모두 TA와 MS의 SEMG의 변화를 나타냈으며, 특히 교 합지를 물린 쪽의 근육 SEMG가 더 큰 활성을 나타냈다 고 보고하였다. 이를 통하여 너무 두껍거나 너무 물리적 특성이 소성을 나타내는 교합점 기록재는 환자가 교합 시 원래 자신의 교합대로 물 수 없을 수도 있으며, 교합지 를 한쪽에 물린 것 만으로도 교합 관계 변화가 나타날 수 있음을 시사하고 있다.

교합점 기록재가 가진 특성이 턱의 위치 변화나 근육의 변화를 나타나게 할 수 있음이 지적되어 왔으나, 더 나아 가 치아 자체에 힘이 가해져 치아의 변위가 나타나게 할 수 있는 가능성도 제기되었다. Helm 등 $^{28}$ 은 교합점 기록 재가 가진 두께 혹은 물리적 특성이 치아의 변위를 나타 나게 할 수 있는지를 알아보았다. 그 결과 교합점 기록재 는 치아의 변위를 일으킬 수도 있는 힘이 가해진 것으로 나타났다. 특이하게도, 두께가 더 두꺼운 교합 실크가 더 얇은 교합지보다 치아에 가한 힘이 적은 것으로 나타났 는데, 이는 두께만이 치아의 변위를 일으키는 요소가 아 님을 시사한다. 즉, 가능한 두께가 얇으면서도 치아에 적
은 힘을 가하는 재료가 더 정확한 결과를 보일 수 있음을 나타낸다.

\section{6. 교합점에 관한 연구 방법들}

교합점 기록재에 관한 대다수의 연구는 교합점이 정확 한가에 초점이 맞춰져 왔다. 정확도를 관찰하기 위한 방 법으로 변수를 설정하고 교합점의 면적을 계산하는 방법 과 수를 세는 방법이 상당수로, 다양한 연구가 진행되었 다고 보기는 힘들다. 또한 교합점의 면적과 그 수가 적절 한지에 대한 평가이지, 그것이 어떻게 하면 위양성을 줄 이거나, 구강 내 환경을 극복하거나 할 수 있는지, 혹은 이런 방법들이 위양성을 줄일 수 있는지 등에 대한 연구 는 보기 힘들었다.

가장 많이 나타난 연구방법은 교합점이 변수에 따라 나타나는 양상이 어떻게 다른지에 관한 것이었다. Schelb 등 $^{12}$ 은 여러 종류의 교합점 기록재가 나타내는 교합점 면 적의 변화를 보았다. 변수로는 교합지의 색상과 두께를 이용하였다. 교합점은 평평한 텅스텐 카바이드 면에 금 속 볼을 이용해 기록하였으며, 면적의 변화는 사진을 촬 영하여 계산하였다. Toledo 등 ${ }^{29}$ 도 유사한 방법으로 인 기하여 교합점의 면적을 계산하였다. 다만, 같은 회사에 서 같은 두께로 출시되었고 색상만 다른 몇몇 제품을 상 호 비교한 점이 특이하였다. Millstein과 Maya ${ }^{11}$ 는 교합 지의 두께, 색상, 매개물질에 따른 교합점의 면적 변화를 보았다. 변수는 교합점 기록재의 종류(필름, 교합지, 실 크, 나일론)와 그 두께였다. 교합점의 기록은 교합기를 이용하여 시행하였고, 교합기의 상악부분을 들어 올렸다 가 놓아 떨어뜨리는 방법으로 교합점을 기록하였다. 기 록한 교합점에 대해 사진촬영을 하여 컴퓨터 소프트웨어 를 이용해 면적을 픽셀단위로 세어 분석하였다. Carossa 등 ${ }^{9}$ 은 유사하게 교합기를 이용하여 교합점을 분석하였 지만, 변수는 전문가와 학생으로 두어 숙련도에 따른 평 가를 하고자 하였다. 하지만 이 연구 역시 두께를 변수로 두었으며, 사진 촬영하여 교합점의 면적을 이용해 평가 했다는 점에서는 유사하다. Brizuela-Velasco 등 ${ }^{10}$ 의 연구 는 in vivo 실험이었지만, 교합점을 형성하여 사진 촬영 후 교합점 면적을 평가했다는 점에서 유사하다. 변수 역 시 두께에 따라 시행하여 크게 다르지 않았다. Saraçoğlu 와 Ozpinar의 연구 ${ }^{5}$ 도 교합기를 이용하여 교합점을 형성 하여 그 면적과 교합점의 수를 비교하는 것이었다. 변수 도 두께, 종류(호일, 실크, 교합지, T-scan ${ }^{\circledR}$ 센서) 등으로 
크게 다르지 않았다. 그 대신 같은 교합지에 대해 교합 시킨 횟수에 따라 교합점의 수 변화를 관찰한 것, 구강 내 환경에서 젖음 환경과 마른 환경에 따른 차이를 관찰한 것은 다른 연구와 구별되는 부분이었다. 하지만 이 실험 역시 교합점의 면적과 교합점의 수를 관찰했다는 측면에 서는 큰 차이가 없었다.

교합력을 변수로 둔 실험들도 교합점의 면적과 수를 중 심으로 분석했다는 사실에선 변함이 없었다. Carey 등 $^{13}$ 의 연구는 교합지의 종류나 두께의 변화를 주진 않고 교합 력만을 이용해 분석했다는 사실에서는 특이한 부분이 있 다. 교합력을 적용할 때 만능시험기를 이용하여 교합력 을 표준화 하였고 전악 모형을 사용하였으며, 모든 실험 에서 동일하게 나타난 위치만을 분석하여 위양성을 줄이 고자 하는 노력이 있었다. 하지만 분석 방법에 있어서 교 합점의 픽셀 단위 분석을 시행한 것은 동일하였다. Saad 등 $^{14}$ 의 연구도 교합력이 교합점에 미치는 영향을 분석하 고자 하였다. 교합기와 만능시험기를 이용해 교합력을 적용하였다는 점과 전악 모형을 사용하였다는 점은 동일 하였으나, 교합점의 수를 셀 때에는 제 1,2 소구치 및 제 1 대구치의 교합점만을 세었다는 점과 교합점 면적을 구 할 땐 제 1 대구치에서 공통적으로 나타나는 점만을 대상 으로 했다는 부분에서 차이가 있었다. 하지만 이 역시 교 합점의 수와 면적을 이용하여 분석했다는 점에선 동일하 였다. Reiber 등 ${ }^{15,19}$ 도 교합지의 두께, 종류, 교합력 등이 미치는 영향을 분석하고자 하였지만 분석 방법에 있어서 큰 차이를 나타내지는 못하였다. 다만 다른 연구에서 수 복물의 종류나 표면 거칠기에 따라 교합점의 양상을 확 인한 바가 있는데, 이러한 변수는 다른 실험에서는 보기 드물었다. Qadeer 등 ${ }^{16}$ 은 T-scan ${ }^{\circledR}$ 상에서 상대적으로 최 대 교합력을 보이는 부위의 결과를 기준으로 삼아 교합 점의 면적과의 관계를 밝히고자 하였다. 교합지의 두께 나 종류의 변수를 차단하고 T-scan ${ }^{\circledR}$ 을 기준으로 삼았다 는 점에서는 특이하나, 교합점 면적을 이용하여 분석하 였다는 점에서는 다른 연구와 차이가 없었다.

교합점 자체의 분석이라는 틀에서 벗어난 연구도 일부 있었다. 교합지 두께에 관해 문제제기를 한 Halperin 등 ${ }^{8}$ 의 연구는 교합지 자체의 물리적 성질에 관한 연구였다. 교 합지의 두께, 소성 변형률, 인장강도 등을 측정하는데 지 나지 않았고 이를 과거의 연구와 비교하는 방법이었다. Kerstein과 Radke ${ }^{17}$ 는 교합점 사진만을 이용하여 임상가 로 하여금 교합점의 해석을 하게 하는 방법으로 교합점 의 주관적인 요소를 밝히고자 하였다. 교합점 해석에 대
한 기준을 T-scan ${ }^{\circledR}$ 상의 결과로 설정하고 이를 임상가들 이 사진만을 보고 제시한 결과와 비교하였다. Sutter의 연 구 $^{18}$ 도 이와 유사하게 진행되었다.

교합점에 관한 연구들을 살펴보면 전반적으로 교합지 에 변수를 두고 그 결과를 교합점의 수나 면적을 이용한 것이 대다수를 차지하고 있었다. 즉, 기본적인 교합지 사 용방법의 틀에서 벗어나지 않고 교합점 자체를 보고자 한다는 것이다. 이에 대해 교합지를 활용하되 분석방법 을 달리 한다든지, 교합지의 신뢰성이나 정확성을 높이 기 위한 방법에 대한 연구는 찾을 수 없었다. 또한, 실제 임상에서는 수복물을 장착할 때 주변치아와 연계하여 평 가하곤 하는데, 이와 관련된 연구 방법은 시도된 바가 없 었다. 더불어, 두께, 교합력 등 일부 요소에 대한 평가가 주를 이루어 실험의 스펙트럼이 다양하지 않은 실정이다 (Table 2).

\section{7. 교합점 연구방법 상 한계점}

교합점 연구방법이 비교적 실험방법이 유사하고 또한 일부 변수에 한해서 실험이 진행되어 온 것은 교합점 연 구가 갖는 한계성 때문이라고도 할 수 있다. 예를 들어, 수복물 간 교합점 기록의 양상을 비교하고자 하더라도 수복물의 형태를 완전하게 동일하게 만들기 어렵고, 만 일 형태를 단순화 시켜서 한다면 임상적 상황을 재현하 지 못한 실험이 된다. ${ }^{12,15}$

교합점 자체가 위양성이 많고 그 면적이나 수에 따라 해석하기엔 정확성이 낮다고 지적되어 교합점이라는 요 소 자체의 신뢰성에 의문이 제기되기도 하였다. ${ }^{11,14}$ 조절 하기 힘들 정도로 다양한 변수가 존재한다는 점도 한계 점으로 지적된다. 가령 서로 다른 회사의 제품을 비교하 거나, 서로 다른 재료를 비교할 때 매개물질, 두께, 색상 등 여러 변수가 존재하게 된다. 하지만 이런 다양한 변 수를 모두 통제 하에 두고 비교하기 어렵다. 두께가 동 일하다 해도 밝혀지지 않은 새로운 변수 때문에 서로 다 른 결과가 나오는 연구결과도 있었다. ${ }^{11}$ 재료에 따라 나 타날 수 있는 변수가 다르다는 점도 지적된 바 있다. 예 를 들어, 필름은 교두에 의한 변형에 저항하려는 속성이 있는 반면, 교합지는 취성이 있고 압축성이 낮아 교합력 에 대해 서로 다른 움직임을 보이려고 한다는 점이다. ${ }^{11}$ 이런 부분은 재료 간 비교 자체가 가능한지에 대해 의문 을 남긴다. 또 매개물질로 사용되는 다양한 성분들(wax, oil, pigments, solvents)은 치아에 색소를 묻히면서 교합 
Table 2. Researches for the reliability of occlusal contact marks

\begin{tabular}{|c|c|c|c|}
\hline Variables & Authors & $\begin{array}{l}\text { In vivo/ } \\
\text { In vitro }\end{array}$ & Indicators \\
\hline $\begin{array}{l}\text { Thickness, strength, } \\
\text { plastic deformation }\end{array}$ & Halperin et al. $^{8}$ (1982) & In vitro & Articulating paper, articulating film, etc. \\
\hline $\begin{array}{l}\text { Thickness, color, } \\
\text { transferring medium }\end{array}$ & Schelb et al. ${ }^{12}(1985)$ & In vitro & Articulating paper, articulating film, etc. \\
\hline $\begin{array}{l}\text { Thickness, occlusal load, } \\
\text { surface morphology, } \\
\text { type of indicator }\end{array}$ & Reiber et al. $^{16}(1989)$ & In vitro & $\begin{array}{l}\text { Articulating paper, articulating film, } \\
\text { articulating silk }\end{array}$ \\
\hline $\begin{array}{l}\text { Thickness, } \\
\text { operator experience }\end{array}$ & Carossa et al. ${ }^{9}(2000)$ & In vitro & Articulating paper \\
\hline $\begin{array}{l}\text { Thickness, color, } \\
\text { transferring medium, } \\
\text { type of indicator }\end{array}$ & Millstein \& Maya ${ }^{11}(2001)$ & In vitro & $\begin{array}{l}\text { Articulating paper, articulating silk, } \\
\text { articulating nylon, articulating film }\end{array}$ \\
\hline Thickness & Brizuela-Velasco et al. ${ }^{10}(2015)$ & In vivo & Articulating paper \\
\hline Thickness & Augusti et al. ${ }^{27}(2015)$ & In vivo & Articulating paper \\
\hline $\begin{array}{l}\text { Type of indicator, } \\
\text { thickness }\end{array}$ & Helms et al. ${ }^{28}(2012)$ & In vitro & $\begin{array}{l}\text { Articulating paper, articulating film, } \\
\text { articulating silk, T-scan }{ }^{B} \text { Sensor }\end{array}$ \\
\hline $\begin{array}{l}\text { Type of indicator, } \\
\text { thickness }\end{array}$ & Toledo et al. $^{29}$ (2014) & In vitro & Articulating paper, articulating film \\
\hline $\begin{array}{l}\text { Type of indicator, } \\
\text { thickness }\end{array}$ & Mitchem et al. ${ }^{31}(2017)$ & In vitro & $\begin{array}{l}\text { Articulating paper, articulating film, } \\
\text { articulating silk, T-scan }{ }^{\circledR} \text { Sensor }\end{array}$ \\
\hline $\begin{array}{l}\text { Surface materials, } \\
\text { surface roughness, } \\
\text { type of indicator }\end{array}$ & Reiber et al. ${ }^{15}$ (1989) & In vitro & Articulating paper, articulating film, etc. \\
\hline Type of indicator & Gazit et al. ${ }^{23}(1986)$ & In vitro & Articulating foil, etc. (photo-occlusion system) \\
\hline Type of indicator & Anderson et al..$^{20}(1993)$ & In vivo & Articulating paper, etc. (shimstock) \\
\hline Type of indicator & Forrester et al. ${ }^{7}$ (2011) & In vivo & $\begin{array}{l}\text { Articulating paper, articulating film, } \\
\text { Articulating silk, T-scan }{ }^{\mathbb{B}} \text { Sensor }\end{array}$ \\
\hline Occlusal load & Carey et al. ${ }^{13}$ (2007) & In vitro & Articulating film \\
\hline Occlusal load & Saad et al. ${ }^{14}(2008)$ & In vitro & Articulating paper, articulating film \\
\hline Occlusal load & Qadeer et al. ${ }^{16}(2012)$ & In vivo & Articulating film, T-scan ${ }^{\circledR}$ Sensor \\
\hline Occlusal load & Kerstein \& Radke ${ }^{17}$ (2014) & In vivo & Articulating paper, T-scan ${ }^{\mathbb{B}}$ Sensor \\
\hline Bulge ductility & Zuccari et al. ${ }^{4}(1997)$ & In vitro & $\begin{array}{l}\text { Articulating paper, articulating film, } \\
\text { T-scan }{ }^{B} \text { Sensor }\end{array}$ \\
\hline $\begin{array}{l}\text { Number of stroke, } \\
\text { dryness/wetness }\end{array}$ & Saraçoğlu \& Ozpinar ${ }^{5}$ (2002) & $\begin{array}{l}\text { In vivo/ } \\
\text { In vitro }\end{array}$ & $\begin{array}{l}\text { Articulating paper, articulating film, } \\
\text { articulating foil, articulating silk, } \\
\text { T-scan }{ }^{B} \text { Sensor }\end{array}$ \\
\hline Transferring medium & Throckmorton et al. ${ }^{25}$ (2009) & In vitro & T-scan ${ }^{\circledR}$ Sensor (with bite guards or not) \\
\hline Production series & Cerna et al. ${ }^{26}(2015)$ & In vitro & T-scan ${ }^{\circledR}$ Sensor (2011 series, 2012 series) \\
\hline
\end{tabular}

점을 표시하기 되는데, 이들이 표면을 부드럽거나 딱딱 하게, 혹은 젖게 만들 수 있으며 이 물질들이 치아의 접촉 에 관여하게 될 수 있다. ${ }^{11}$ 이러한 점들은 교합점 기록재 의 재료 간 비교나 제품 간 비교가 어렵게 만드는 요인이 될 수 있다. 그 외에도, 교합점 기록재의 사용방법이 서 로 다른 점도 비교 연구가 어렵게 만드는 요인이 된다. T-
$\operatorname{scan}^{\circledR}$ 센서는 하드웨어 장비에 장착하여 사용하는데 반 해 보통 교합지는 교합지 홀더에 장착하여 사용하거나 아예 장착하지 않고 사용하는 경우도 있다. 이러한 사용 법의 차이를 극복하기 위해 동일한 방법으로 통일시킨 경우 실제의 임상적 차이를 반영하지 못한다는 한계점이 나타나게 된다. ${ }^{7}$ 
교합점 기록재가 교합 자체를 변화시킬 수 있다는 사 실은 그 자체로 연구의 한계점이 될 수 있다. ${ }^{7,27,28,30}$ 임상 적으로 교두 간 간섭은 각 치아에 대해 서로 다른 교합력 분산을 야기하며, 동일한 순간의 접촉이 일어날 수 없게 한다. ${ }^{31}$ 교합지가 서로 다른 순간에 닿게 되어 교두 간 간 섭과 유사한 효과를 나타낸다면 교합지 자체가 교합 자 체를 변화시켜 정확한 결과를 얻을 수 없게 한다. ${ }^{11}$ 이런 부분들은 실험과정에서도 마찬가지로 조절하기 힘든 변 수로서 작용된다고 할 수 있다.

그 외에도 교합점을 T-scan ${ }^{\circledR}$ 의 결과와 비교한 경우 ${ }^{17,18}$ T-scan ${ }^{\circledR}$ 이 과연 기준으로 사용할 만큼 정확한가에 대한 논쟁이 있고 ${ }^{5,7,25,26}$ 실제 임상에서 얻을 수 있는 여러 정보 들을 배제한 체 결론을 냈다는 점에서도 한계점이 지적 된다. ${ }^{17}$ 또 Malta Barbosa 등 ${ }^{32}$ 은 교합지나 교합 호일의 두께를 직접 재어 회사에서 제시한 값과 비교한 연구에 서 그 값이 부정확함을 지적하였으며, 이는 회사에서 제 시한 값을 이용한 여러 교합점 기록재 연구에 대한 전반 적인 문제제기로 이어질 수 있다.

\section{결론}

교합점 기록재는 두께, 가해지는 교합력, 구강 내 습윤 환경 뿐만 아니라 사용 횟수, 재료의 물리적 특성, 매개 물질 등 많은 변수가 결과에 영향을 끼칠 수 있다. 변수 중에 조절 가능한 요소인 사용 횟수, 구강 내 습윤 환경, 두께 등은 가급적 통제하여 정확도를 향상시킬 수 있다. 특히, 두께와 재료의 물리적 특성은 환자로 하여금 교합 의 변화를 야기하여 교합분석의 신뢰도를 낮출 수 있다 는 점에서도 유의해야 한다. 그러므로, 교합지는 가능하 면 매 회 새것을 사용하고 구강 내 건조상태를 확보하며 특별한 이유가 없다면 가급적 얇은 교합지를 사용하여야 한다.

교합점을 분석할 때 교합점의 면적은 교합력과는 관계 가 없음을 상기하여야 한다. 또 교합점의 면적은 시행 때 마다 달라질 수 있는, 즉 신뢰도가 낮은 요소임을 기억하 여야 한다. 그러므로 교합점 만을 이용하여 단독으로 분 석하는 것은 지양하여야 하며, 심스탁 혹은 T-scan ${ }^{\circledR}$ 과 같 은 양적 방법의 보조수단을 함께 활용해야만 교합점 분 석 및 교합조정을 시행 시 더 나은 결과를 얻을 수 있을 것이다.

\section{ORCID}

Chang-Hwan Kim https://orcid.org/0000-0002-74168127

Dae-Gon Kim https://orcid.org/0000-0003-3304-159X Kyung-Ho Ko https://orcid.org/0000-0002-1260-8844

Yoon-Hyuk Huh https://orcid.org/0000-0003-4072-5199

Lee-Ra Cho https://orcid.org/0000-0003-3989-2870

Chan-Jin Park https://orcid.org/0000-0003-4734-214X

\section{References}

1. Dawson PE. Functional occlusion: from TMJ to smile design. 1st ed. Philadelphia; Elsevier Health Sciences; 2006. p.394-417.

2. McNeill C. Science and practice of occlusion. 1st ed. Illinois; Quintessence Publishing; 1997. p.40418.

3. Okeson JP. Management of temporomandibular disorders and occlusion. 7th ed. Philadelphia; Elsevier Health Sciences; 2014. p.443-56.

4. Zuccari AG, Oshida Y, Okamura M, Paez CY, Moore BK. Bulge ductility of several occlusal contact measuring paper-based sheets. Biomed Mater Eng 1997;7:265-70.

5. Saraçoğlu A, Ozpinar B. In vivo and in vitro evaluation of occlusal indicator sensitivity. J Prosthet Dent 2002;88:522-6.

6. Sharma A, Rahul GR, Poduval ST, Shetty K, Gupta $\mathrm{B}$, Rajora V. History of materials used for recording static and dynamic occlusal contact marks: a literature review. J Clin Exp Dent 2013;5:e48-53.

7. Forrester SE, Presswood RG, Toy AC, Pain MT. Occlusal measurement method can affect SEMG activity during occlusion. J Oral Rehabil 2011;38: 655-60.

8. Halperin GC, Halperin AR, Norling BK. Thickness, strength, and plastic deformation of occlusal registration strips. J Prosthet Dent 1982;48:575-8.

9. Carossa S, Lojacono A. Schierano G, Pera P. Evaluation of occlusal contacts in the dental laboratory: influence of strip thickness and operator experience. Int J Prosthodont 2000;13:201-4.

10. Brizuela-Velasco A, Álvarez-Arenal Á, Ellakuria- 
Echevarria J, del Río-Highsmith J, Santamaría-Arrieta $G$, Martín-Bianco N. Influence of articulating paper thickness on occlusal contacts registration: a preliminary report. Int J Prosthodont 2015;28:3602.

11. Millstein P, Maya A. An evaluation of occlusal contact marking indicators: a descriptive quantitative method. J Am Dent Assoc 2001;132:1280-6.

12. Schelb E, Kaiser DA, Brukl CE. Thickness and marking characteristics of occlusal registration strips. J Prosthet Dent 1985;54:122-6.

13. Carey JP, Craig M, Kerstein RB, Radke J. Determining a relationship between applied occlusal load and articulating paper mark area. Open Dent J 2007;1:17.

14. Saad MN, Weiner G, Ehrenberg D, Weiner S. Effects of load and indicator type upon occlusal contact markings. J Biomed Mater Res B Appl Biomater 2008;85:18-22.

15. Reiber T, Fuhr K, Hartmann H, Leicher D. Recording occlusal indicators. Introduction to occlusal surface materials and roughness. ZWR 1989;98:75661.

16. Qadeer S, Kerstein R, Kim RJ, Huh JB, Shin SW. Relationship between articulation paper mark size and percentage of force measured with computerized occlusal analysis. J Adv Prosthodont 2012;4:712.

17. Kerstein RB, Radke J. Clinician accuracy when subjectively interpreting articulating paper markings. Cranio 2014;32:13-23.

18. Sutter BA. A digital poll of dentists testing the accuracy of paper mark subjective interpretation. Cranio 2017;9:1-8.

19. Reiber T, Fuhr K, Hartmann H, Leicher D. Recording pattern of occlusal indicators. I. Influence of indicator thickness, pressure, and surface morphology. Dtsch Zahnarztl Z 1989;44:90-3.

20. Anderson GC, Schulte JK, Aeppli DM. Reliability of the evaluation of occlusal contacts in the intercuspal position. J Prosthet Dent 1993;70:320-3.

21. Harper KA, Setchell DJ. The use of shimstock to assess occlusal contacts: a laboratory study. Int J Prosthodont 2002;15:347-52.

22. Maness WL. Laboratory comparison of three occlusal registration methods for identification of induced interceptive contacts. J Prosthet Dent 1991; 65:483-7.

23. Gazit E, Fitzig S, Lieberman MA. Reproducibility of occlusal marking techniques. J Prosthet Dent 1986;55:505-9.

24. Kerstein RB, Lowe M, Harty M, Radke J. A force reproduction analysis of two recording sensors of a computerized occlusal analysis system. Cranio 2006;24:15-24.

25. Throckmorton GS, Rasmussen J, Caloss R. Calibration of T-Scan sensors for recording bite forces in denture patients. J Oral Rehabil 2009;36:636-43.

26. Cerna M, Ferreira R, Zaror C, Navarro P, Sandoval P. Validity and reliability of the T-Scan ${ }^{\circledR}$ III for measuring force under laboratory conditions. J Oral Rehabil 2015;42:544-51.

27. Augusti D, Augusti G, Re D, Dellavia C, Giannì AB. Effect of different dental articulating papers on SEMG activity during maximum clenching. J Electromyogr Kinesiol 2015;25:612-8.

28. Helms RB, Katona TR, Eckert GJ. Do occlusal contact detection products alter the occlusion? J Oral Rehabil 2012;39:357-63.

29. Toledo MF, Jóias RP, Marques-Iasi YS, Neves AC, Rode Sde M. Thickness and marking quality of different occlusal contact registration strips. J Appl Oral Sci 2014;22:516-21.

30. Mitchem JA, Katona TR, Moser EAS. Does the presence of an occlusal indicator product affect the contact forces between full dentitions? J Oral Rehabil 2017;44:791-9.

31. Korioth TW. Number and location of occlusal contacts in intercuspal position. J Prosthet Dent 1990; 64:206-10.

32. Malta Barbosa J, Urtula AB, Hirata R, Caramês J. Thickness evaluation of articulating papers and foils. J Esthet Restor Dent 2018;30:70-2. 


\section{교합점 기록재와 교합점 표식의 신뢰도에 관한 고려사항}

\section{김창환, 김대곤, 고경호, 허윤혁, 조리라, 박찬진*}

강릉원주대학교 치과대학 치과보철학교실 및 구강과학연구소

교합점 기록재를 통해 교합점을 분석하는 방법이 신뢰할 만한가에 대해서는 사용하는 방법이 결과에 미칠 수 있는 영향 을 고려해야 한다. 교합점 기록은 교합점 기록재료와 두께, 교합력, 사용 횟수, 재료의 물리적 특성, 매개 물질 등 많은 변 수에 의해서 정확도, 신뢰도에 영향을 받을 수 있다. 그럼에도 불구하고 교합점 기록재에 대한 연구는 환자의 교합력과 기록재의 두께 등 일부 요소에 대한 평가가 주를 이루어 다양성이 부족하다. 변수를 통제하기 위해 교합지는 가능하면 매 회 새것을 사용하고 구강 내 건조상태를 확보하며 가급적 얇은 교합지를 사용하여야 한다. 또한, 한가지 방법만으로 분석하는 것은 지양하여야 하며, 보조 수단을 함께 활용할 것이 추천된다.

(구강회복응용과학지 2018;34(3):147-56)

주요어: 교합점; 교합점 기록재; 신뢰도; 정확성; 타당성

*교신저자: 박찬진

(25457)강원도 강릉시 죽헌길 7 강릉원주대학교 치과대학 치과보철학교실

Tel: 033-640-3153 | Fax: 033-640-3103 | E-mail: doctorcj@gwnu.ac.kr

접수일: 2018년 5월 13일 | 수정일: 2018년 6월 11일 | 채택일: 2018년 6월 14일 